4. En este sentido podriamos decir que el Marx "liberal está más cerca del realismo de Aristôteles que el propio Domènech, pues pensaría, como el griego, que la tangente álica es posible porque proporciona la base material de la existencia. ¿Por qué no pensar que Marx busca esas condiciones materiales, pero ya no en el reducido marco de la polis, sino en el de la xcosmopolts $n$, intentando, además, erradicar las situaciones de injusticia y explotación inherentes a aquẹlla?
5. El concepto de anecesidades básicas” es difícil de definir. Pero para nuestro propósito valdrá la siguiente definición: wun individuo tiene sus necesidades básicas cuando no muere de inanición, tiene un techo mínimamente seguro donde cobijarse y abrigo regular para protegerse de las inclemencias del tiempos. Es suficiente, cremos, porque una gran parte de la población mundial se halla por debajo de esos minimos.

\title{
Para una lectura actual de la Crítica del Juicio
}

\author{
VALERIANO BOZAL \\ Universidad Complutense
}

1

Las razones para la lectura actual de la Crítica det Juicio son varias y de diversa condición. Algunas estrictamente académicas, como la influencia de esta obra sobre las reflexiones estéticas posteriores o su papel en el sistema de la filosofía kantiana, otras, y a estas deseo referirme aquí, desbordan su ámbito, a la vez que lo incluyen, y sitúan la Crítica del Juicio en el centro de una consideración original sobre los orígenes de la. modernidad.

Puede abordarse esta perspectiva desde una posición a primera vista más académica: el origen de la disciplina estética. Sabido es que la estética en cuanto disciplina autónoma surge en el siglo xvul. Hasta entonces habia habido reflexiones estéticas - y una historia del pensamiento estético sc remonta siempre a los griegos, mundo en el que se perfilan algunos de los conceptos fundamentales de lo estético y de la disciplina estética--, pero tales pensamientos se producen habitualmente en el marco de teorizaciones más amplias y al margen de una delimitación disciplinar. En el Siglo de las Luces, por el contrario, se asiste a una preocupación específica por lo estético que atañe incluso a su denominación. El término "estética» no posee todavía el sentido con que actualmente lo entendemos, y en el mismo sistema kantiano se puede apreciar la dificultad de la precisión. En la Crítica de la razón pura "estétican hace referencia al momento primero, intuitivo o sensible del proceso de conocimiento, y tanto en la Critica del Juicio como en cl texto que ya se conoce como primera introducción a la "Critica del Juicio", el filósofo se ve obligado a llamar la atención sobre los dos sentidos del término: primer momento del conocimiento y efecto del gusto o análisis de tal efecto estético (estético y estética, respectivamente). ${ }^{1}$

Esta dualidad no es una cuestión meramente terminológica y, a pesar de lo que afirma Kant en el texto citado en la nota, creo que hay algo más que una "carencia de otra expresión" para el uso de «estética». Existe un punto de contacto entre estética (intuición 
sensible) y estética (gusto y placer estéticos), y ese punto cs contral a ambas: la inmediatez que lo sensible supone y que lo estético exige, inmediatez en la que justamente centrará Kant su análisis del juicio de gusto (juicio no mediado por conceptos).

La inmediatez. hace referencia a una relación directa entre sujeto y objeto. Ahora bien, precisamente por la ausencia de mediaciones «intelectuales», el conocimiento que tal relación suscita aparece tradicionalmente como un conocimiento de lo singular, sin capacidad de generalización, menor, paso para momentos posteriores y más completos. La historia del pensamiento estético, fundamentada en gran medida en la teoría griega de la mimesis tal como la habían expuesto Platón y, sobre todo, Aristóteles, se vio obligada a introducir rasgos que corrigieran este aspecto y para ello recurrió a la Idea neoplatónica y a un tipo de conocimiento que pudiera parangonarse, en este punto, con el conocimiento intelectual o reflexivo. Mas el desarrollo del empirismo en el siglo xvIII y de una teoria del gusto que está ya vigente en los primeros años de la centuria, obliga a un replanteamiento de la cuestión. En ese replanteamiento la estética se configura como una disciplina con un objeto propio, lo estético.

Las formas de dar solución al problema planteado serán diversas: desde las que entienden el placer estético como resultado de la intuición sensible, a veces su residuo, hasta las que apuntan a la imaginación como facultad en cuya órbita puede producirse el placer de un conocimiento sensible que no dice nada verdadero - sólo imaginario- de las cosas estéticamente representadas (ya sea reproducidas artísticamente, ya contempladas en la naturaleza). La propuesta kantiana es mucho más radical: no hay conocimien- to en el juicio de gusto, que es, frente a los juicios de conocimiento, determinantes, un juicio reflexionante, un juicio que, lejos de poner lo singular bajo la generalidad del concepto, busca esa generalidad sin llegar nunca a ella.

\section{2}

A partir de aquf, el comentario puede desarrollarse en el análisis de la influencia de la Critica sobre el posterior romanticismo 0 , como ya indiqué, sobre su lugar y papel en el sistema kantiano. Pero desearía detenerme, no entrar en esas vías de reflexión, que por otra parte han, sido suficientemente transitadas, y preguntarme por la razón de esa inmediatez, por la radicalidad con que Kant plantea el problema.

En principio, podría hablarse de una radicalidad teórica, de un rigor teórico. La afirmación de la esteticidad exige el rechazo de cualquier mediación, y en ese rechazo el del concepto es fundamental, así como lo es cualquier reducción de la esteticidad a producto subsidiario del conocimiento sensible, en cuyo caso carecería de ámbito específico, o a cualquier explicación psicologista - de fisiologismo habla Kant a propósito de Burke al analizar la idea de lo sublime-, que eliminaría necesidad y universalidad de lo estético. Al rechazar estos tres caminos, la radicalidad kantiana convierte la inmediatez en el centro de la reflexión e inaugura un ámbito propio de lo estético.

En este ámbito se lleva a cabo una inversión, una «revolución copernicana» similar a la que había tenido lugar en la Critica de la razón pura, y es esa inversión la que fundamenta la posibilidad misma del ámbito.

Un tópico tradicional del pensamiento estético es la afirmación según la cual la imagen artística (o la contemplación estética de la naturaleza) intro- 
duce unidad allí donde para la intuición sensible sólo existe fragmentariedad. El origen de la concepción mimética de la representación en el teatro griego -que pasa al pensamiento estético- suponía la unidad de dos mundos que posteriormente iban a separarse cada vez más, y esta idea, casi recuerdo, de la unidad no se perdió nunca aunque sufrió abundantes cambios en la consideración de su naturaleza y llegó a convertirse, precisamente en la época en que el filósofo escribe, en utópica concepción del pasado como futuro.

La reflcxión kantiana, lejos de ignorar este problema lo sitúa en el punto central, ahora bien, invirtiéndolo. Hasta ahora el pensamiento estético había venido concibiendo la unidad del mundo como algo que se alcanzaba a través de un conocimiento específico (estético) pero que, en cualquier caso, era algo que estaba dado, que pertenecía al objeto (y eso es lo único que quiere decir "dado" en esta nota). Kant fundamenta esa unidad en el principio trascendental del juicio, principio de la finalidad formal de la naturaleza tal como lo explica en el apartado quinto de la Introducción a la Critica y lo emplea después en la misma Crítica.

La conexión de los fenómenos es pensada a partir de un principio de conexión que perfila necesidad en aquella contingencia empírica, aunque tal necesidad no se encuentre o aprecie en lo contingente (precisamente porque es contingente). Este es un principio supuesto, no dado, presente como condición de la conexión de los fenómenos bajo leyes particulares, sin el cual ni siquiera podría hablarse de naturaleza, tampoco de experiencia. Se trata de un principio trascendental, y esto es importante recordarlo porque, primero, no se «encuentra" en el objeto, del que sólo tenemos intuiciones singulares, segundo, no dice nada de la cuali- dad del objeto sino de su relación al sujeto $\mathrm{y}$, tercero, no es puesto o proyectado por el sujeto sobre el objeto, no es fundamento sino condición, $\mathrm{y}$ ese ser condición, sin el cual no se puede tener experiencia de la naturale$z a$, es lo que permite hablar dc un principio trascendental.

La unidad de la naturaleza no viene determinada por la índole del objeto. ni en él podemos buscarla (no es, por tanto, cuestión de la agudeza o modalidad del conocimiento), tampoco es proyección del sujeto sobre el objeto, con lo cual lo transformaría y haría a su imagen, es condición de la experiencia, presente en la relación que ella implica, pero no dada en uno u otro de los extremos de esa relación. Es, por ello mismo, principio inmediato $y$ de la inmediatez, pues sin él ninguna experiencia sería posible.

Cuando en los epigrafes 45 y 46 de la Crítica establece Kant la relación inversa entre arte y naturaleza, sitúa este principio en el centro de su reflexión estética: «La naturaleza era bella cuando al mismo tiempo parecía ser arte, y el arte no puede llamarse bello más que cuando teniendo nosotros consciencia de que es arte, sin embargo parece naturaleza» (trad. de M. García Morente). El parecer ser arte de la naturaleza no es sino el parecer de la unidad como cualidad de la misma naturaleza, como si respondiera a una finalidad. El parecer ser naturaleza de la belleza es el parecer que carece de finalidad, que no ha sido hecha (la obra) artificialmente segín reglas que proporcionan la unidad. Al ofrecerse de esta forma, al ocultar tales reglas y "simular un origen natural", el arte presenta o expone - preferiría decir representa- lo que la naturaleza es en la experiencia, respetando precisamente la trascendentalidad del principio de finalidad, que no aparece como cuali- 
dad del objeto (ahora artístico), sino como condición representada. Lo que el arte expone o representa es el principio trascendental de la experiencia en la que el hombre puede reconocer -la tiene delante, en el objeto artístico- su condición no mediada. La capacidad del genio reside en poner delante nuestro la imagen de la naturaleza en nuestra experiencia, como única naturaleza posible y como posible sólo en la experiencia. Por tanto, la íntima e indestructible conexión entre hombre y naturaleza que en nuestra experiencia acontece -unidad sin la que la experiencia sería imposible y términos como kexperiencia» o "naturaleza» carecerian de sentido propio-, y en esa representación nos reconocemos. Simultáneamente, Kant señala que esa conexión no es algo dado, no es cualidad sino condición, sin que exista una base empírica para ella, la que tradicionalmente viene considerándose base firme, tampoco una base ideal, que una supuesta intuición de la idea sería capaz de captar, acomodando en tal intuición y su representación artística lo aparente y fragmentario a lo ideal y único.

Aquello que la obra de arte expone o representa no es cualidad del sujeto ni del objeto, ni lo proyectamos ni lo encontramos, es el punto de vista, el lugar desde el cual pueden apreciarse las cualidades, el punto de vista sobre el mundo (por lo que la obra de arte no puede considerarse como una forma de conocimiento). Semejante lugar carece de fundamento, es condición de tal mirar y sólo puede apoyarse en su interna necesidad, no en algo exterior y firme. La inmediatez cumple así su más radical destino, aquel en que todo ha de crearse porque nada está dado. La inmediatez se presenta ahora como ausencia de algo en que apoyarse, y esa negatividad acompaña siempre a la experiencia. Tal negatividad inaugura la época moderna. La unidad de hombre y naturaleza ni es algo dado ni algo que podamos alcanzar, es supuesto para cualquier fundamento, pero un supuesto que carece, a su vez, de otra fundamentación que no sea su carácter de condición, supuesto siempre arriesgado, siempre perdido, inseguro. La obra de arte, indica Kant, tiende a un concepto, nos remite a él, pero sin llegar nunca a alcanzarlo. Ese "más allá» a que la imagen artística nos remite es, propiamente hablando, un más acá, el lugar no mediado desde el cual atisbar las cosas. Los extravios de las formas modernas han pretendido aquel alcance, situar la idea en algún punto, por lejano que fuese (de ahi su extravio), pero nunca pudieron eliminar la original tensión kantiana, y esa tensión es siempre sospecha sobre sus pretensiones.

\section{3}

Al analizar los modos de mirar el mundo, del mirar estético, Kant mantiene una actitud restrictiva. Desde principios de siglo tales modos habian transformado y enriquecido el dominio del gusto, Addison había hablado de lo bello, lo sublime y lo pintoresco, Burke de lo bello y lo sublime, incluso los más estrictos neoclásicos, como Mengs, procuraron dar entrada, a través de la vía permitida por las poéticas clasicistas tradicionales, al estilo, a los nuevos conceptos y hablaron de un estilo bello, pero también de otro naturalista, expresivo, cte.

La restricción kantiana reduce aquel mirar al de la belleza. Su análisis de lo sublime convierte a éste en efecto de una idea de la razón suscitada por la incapacidad de la intuición sensible para dar cuenta de la magnitud o el dinamismo de la naturaleza. La presencia de tal idea alcja lo sublime del horizonte no mediado de la estética. Sin embargo, la incidencia posterior de la 
concepción kantiana fue, en este punto, grande y su explicación de lo sublime alcanzó más efecto incluso que la teoría, por él calificada de fisiologista, de Burke, sin que la negación de la esteticidad de lo sublime fuera excesivamente respetada.

La positividad y superioridad racional del hombre sobre la naturaleza, precisamente en el momento de mayor inanidad ante la fuerza de ésta, es una de las razones fundamentales para explicar tal influencia en el desarrollo posterior del romanticismo, que encontraba asi la posibilidad de un «consuelo estético». Pero el asunto que ahora me preocupa no es ese, es el motivo por el que Kant restringe las modalidades del mirar estético al mirar de la belleza.

Kant no se interesa por los modos del mirar estético (creo que éste es punto central en una lectura actual de la Crítica), analiza la condición misma de ese mirar, que es una representación. No hay sujeto, aunque exista, salvo en la representación que es, antes que otra cosa, la experiencia, y tal representación lo es de la naturaleza y del sujeto en su relación a ella. Al senalar que no hay sujeto quiero decir que el sujeto carece de identidad alguna fuera de la representación -..ni siquiera posee la de sujeto-y que, por consiguiente, sólo en ella es. Pero también se dice que ese representarse no es un autorrepresentarse en el sentido tradicionalmente solipsista que ha recibido este término, pues sólo es posible en la experiencia de la naturaleza y no al margen de ella. La tensión que introduce la negatividad de este spunto de partidas puede conducir, y de hecho ha conducido, a la búsqueda de fundamentos más firmes en los que la autorrepresentación tradicionalmente entendida ha jugado su papel. Pero la radicalidad de la reflexión kantiana ha ensombrecido, a su vez, tales «escapa- torias", para las que siempre ha sido un horizonte de recuerdo e inquietud.

En este punto me parece adecuado señalar que la Critica del Iuticio ha dado un paso adelante en la dirección "prometida» por la Crítica de la razón pura. En ésta el representarse del sujeto se vislumbra como una exigencia en la construcción de la trascendentalidad, pero tal asunto no era expresamente tematizado.

El sujeto trascendental kantiano cs un sujeto ilustrado, un sujeto de conocimiento. Kant se representa al "yo mismo" como "yo pienso" en la perspectiva del «yo conozco». La presencia del ayo mismow es requerida por la sintesis de la imaginación trascendental y en cuanto fundamentación de tal síntesis: la diversidad de las intuiciones requicre para su unidad en el conocimiento - -ahora en la intuición, en el "primer momento" del conocer - un "yo mismo" del que todas son intuiciones. La sintesis de la imaginación $^{2}$ es una síntesis de hechos basada en la sucesión, permanencia y simultaneidad, "formalidad de hechos" que remite por analogia a las categorias de la relación. Son propias de esta formalidad su necesidad y universalidad, pues no afecta a este o aquel hecho sino a todos, no se concluye de dato empírico alguno sino que es necesaria para cualquier dato empírico como su condición trascendental.

El paso del "yo mismo" al "yo pienso», es decir el paso de un sujeto de la síntesis de la intuición a la síntesis del entendimiento, se produce en la propia representación del sujeto: al advertir, representándosela, la legalidad de la formalidad de los hechos se "toma conciencia» de su carácter normativo y, así, del "yo mismo" como "yo pienson: en la representación del sujeto de la intuición adviene el sujeto de conocimiento. No existc ningún fundamento externo de ese paso, el único es la capacidad del sujeto para representarse, lo que sólo pue- 
de hacer -y en este punto la Critica del Juicio es terminante y esclarecedora-. "con ocasión» de la representación (intuición) de una cosa, es decir, en la experiencia de la naturaleza. ${ }^{3}$

Podria hablarse, entonces, de tres niveles del sujeto: sujeto de la intuición, sujeto de la representación (estética) y sujeto del conocimiento. El análisis de la Crítica del juicio se centra en el que llamo segundo nivel, que determi- na su lugar en la arquitectura del sistema kantiano y perfila con nitidez la diferencia entre estética (intuición sensible) y estética (juicio de gusto, sensibilidad). La radicalidad de la reflexión de la Critica encuentra sus orfgenes en la ausencia de fundamento exterior, en la ausencia de mediación sobre la que apoyar la condición de tal sujeto $y$, así, en la negatividad que siempre ha de «acompañarle».
1. "La expresión "modo estético de representacion" es absolutamente inequrvoca, si por ella entendemos la relación de la representación con un objeio, en cuanto fenómeno, con el fin de conocerlo; porque entonces "estético" significa que la forma de la sensibilidad (como es afectado el sujeto) se añade necesariamente a tal representación y es transmitida necesariamente al objeto (pero sólo como fenómeno). Así, podría baber una estética trascendental, en cuanto ciencia perteneciente a la facultad del conocimiento. Sin embargo, desde hace mucho tiempo se acostumbra a Ilamar a un modo de representación "estético", es decir, sensible, también en el sentido de que en sl no se trata de la relación de una representación con la facultad de conocimiento, sino con el sentimiento de placer y displacer. Si bien acostumbramos a llamar a este sentimiento (segưn esta denominación) también "sentido"(modificación de nuestro estado), porque carecemos de otra expresión, no obstante no se trata de un sentido objetivo, cuya determinación sea usada para el conocimiento de un objeto (porque intuir algo, o bien reconocerlo, con placer no es una mera relación de la representación con el objeto, sino una receptividad del sujeto), sino que no contribuye en absoluto al conocimiento del objeton, Primera introducción a la "Critica del Juicio". Madrid. Visor, 1987 (trad. de J.L. Zalabardo).

2. Existen diversidad de interpretaciones sobre la naturaleza de la faculad de esta síntesis y,-por tanto, sobre la naturaleza misma de la formalidad, e incluso es perceptible cierta vacilación en la propia reflexión kantiana (diferencia entre la primera y la segunda edición de la Crttica). La diversidad de las interpretaciones no es ociosa para el tema aquí abordado, pero excede los límites de las presentes notas. Es posible entender la existencia de una facultad en sentido estricto - tal parece ser el criterio al que se aproxima villacanas (J. Villacañas: Racionalidad critica. Intro ducción a la filosofia de Kant, Madrid, Tecnos, $1987,117)$ - si bien el texto de Kant es vacilante incluso en su formulación. La consideración de imaginación $y$ entendimiento como facultades acentua la cesura entre ambas y por tanto entre la sintesis do una y otro. La consideración de la inaginación como una raíz comûn - tal parece ser el pensamiento de Heidegger (M. Heidegger: Kant und das Probtem der Metaphysik, 1929 [trad. cast., 1954, 119]) - e incluso la afimación de una raíz común al margen de que sea o no la imaginacion, de que sea o no facultad - parece la propuesta de Martinez Marzoa (F. Martínez Marzoa: Desconocida raiz comín (Estudio sobre la teoria kantiana de lo bellol, Madrid, Visor, 1987)-, tiende a reducir la amplitud de la cesura y a considerar todo el conocimiento como un proceso homogéneo y comapleto.

3. Las interpretaciones que afirman la cesura entre imaginación y entendimiento no pueden convertir a éste en fundamento de la actividad de aquella, pues no tendría, todavia, normas en que fundarla (a menos que presupongan el entendimiento y sus reglas, con lo que se destruiría la cesura inicialmente defendida). Las interpretaciones que apoyan la continuidad imaginación y entendimiento y acentuan el carácter procesual no segmentado del conocer, o bien se inclinan por la imaginación como creadora de esquemas que el cntendimiento emplea, y este empleo xconstituye precisamente el ser originario del entendimienton (Heidegger, op. cit., 130), o bien se centran. en una raíz común de intuición y entendimiento que no es otra cosa que el sujeto de representación. 